\title{
Microglia Are Essential to Masculinization of Brain and Behavior
}

\author{
Kathryn M. Lenz, Bridget M. Nugent, Rachana Haliyur, and Margaret M. McCarthy \\ Department of Pharmacology, School of Medicine, University of Maryland Baltimore, Baltimore, Maryland 21201
}

Brain sexual differentiation in rodents results from the perinatal testicular androgen surge. In the preoptic area (POA), estradiol aromatized from testosterone upregulates the production of the proinflammatory molecule, prostaglandin $\mathrm{E}_{2}\left(\mathrm{PGE}_{2}\right)$ to produce sex-specific brain development. $\mathrm{PGE}_{2}$ produces a two-fold greater density of dendritic spines in males than in females and masculinizes adult copulatory behavior. One neonatal dose of $\mathrm{PGE}_{2}$ masculinizes the POA and behavior, and simultaneous treatment with an inhibitor of additional prostaglandin synthesis prevents this masculinization, indicating a positive feedforward process that leads to sustained increases in $\mathrm{PGE}_{2}$. The mechanisms underlying this feedforward process were unknown. Microglia, the primary immunocompetent cells in the brain, are active neonatally, contribute to normal brain development, and both produce and respond to prostaglandins. We investigated whether there are sex differences in microglia in the POA and whether they influence developmental masculinization. Neonatal males had twice as many ameboid microglia as females and a more activated morphological profile, and both estradiol and PGE 2 masculinized microglial number and morphology in females. Microglial inhibition during the critical period for sexual differentiation prevented sex differences in microglia, estradiol-induced masculinization of dendritic spine density, and adult copulatory behavior. Microglial inhibition also prevented the estradiol-induced upregulation of $\mathrm{PGE}_{2}$, indicating that microglia are essential to the feedforward process through which estradiol upregulates prostaglandin production. These studies demonstrate that immune cells in the brain interact with the nervous and endocrine systems during development, and are crucial for sexual differentiation of brain and behavior.

\section{Introduction}

Microglia are the primary immunocompetent cells of the brain, responding to injury and inflammation with production of proinflammatory molecules, including prostaglandins, nitric oxide, cytokines, and chemokines (Gehrmann et al., 1995; Kim et al., 2005). After infection, traumatic injury, stroke, or in neurodegenerative disease, microglia undergo a dramatic change from a ramified, quiescent morphology to an ameboid, activated morphology (e.g., Ling and Wong, 1993; Munn, 2000; Vargas et al., 2005) and can play both damaging and neuroprotective roles (Marchetti et al., 2005; Streit et al., 2005). Microglia are also in a primarily activated state in the healthy neonatal brain (Ling et al., 1990; Wu et al., 1992; Ling and Wong, 1993; Dalmau et al., 1997; Schwarz et al., 2012) and play a demonstrated role in normal neurodevelopmental processes, including axon guidance, neurite growth, synaptic pruning, and apoptosis (Kingham et al., 1999; Polazzi and Contestabile, 2002; Marin-Teva et al., 2004; Mallat et al., 2005; Tremblay et al., 2011; Schafer et al., 2012).

Microglia are in a primarily activated state during the early postnatal period, and transition to a largely ramified state by the

Received March 14, 2012; revised Dec. 10, 2012; accepted Dec. 10, 2012.

Author contributions: K.M.L., B.M.N., and M.M.M. designed research; K.M.L., B.M.N., and R.H. performed research; K.M.L. analyzed data; K.M.L. and M.M.M. wrote the paper.

This work was supported by NIH Grants R01MH52716 (M.M.M.), F32NS076327 (K.M.L.), and T32NS007375. The authors declare no competing financial interests.

Correspondence should be addressed to Dr. Kathryn M. Lenz, 655 W. Baltimore Street, BRB 5-014, Baltimore, MD 21201. E-mail:kmlenz@umaryland.edu.

DOI:10.1523/JNEUROSCI.1268-12.2013

Copyright $\odot 2013$ the authors $\quad 0270-6474 / 13 / 332761-12 \$ 15.00 / 0$ third postnatal week (Schafer et al., 2012; Schwarz et al., 2012). This temporal window of basal microglial activity corresponds to the critical period for hormonally mediated sexual differentiation of the brain. During this critical period, the perinatal androgen surge from the male testis provides testosterone to the brain, which is then locally aromatized into estradiol to induce brain masculinization and defeminization (McCarthy et al., 2009). The result is a brain that mediates adult male copulatory behavior, but not female-typical behaviors, including lordosis and maternal behavior.

The preoptic area (POA) is a highly sexually dimorphic brain region necessary for the expression of the full compliment of adult male sex behavior. The major morphological sex differences in the POA are organized by the perinatal actions of estradiol. At the gross morphological level, the sexually dimorphic nucleus of the POA is 5- to 7-fold larger in males than females (Gorski et al., 1978; Davis et al., 1996). At the level of individual cells, males have 2-3 times more dendritic spines on neurons and more complex astrocytic morphology than females (Amateau and McCarthy, 2002b, 2004). Estradiol in the POA upregulates synthesizing enzymes for the proinflammatory molecule, prostaglandin $\mathrm{E}_{2}\left(\mathrm{PGE}_{2}\right), \mathrm{COX}-1$, and COX-2, and $\mathrm{PGE}_{2}$ is both necessary and sufficient to masculinize dendritic spine density and male copulatory behavior (Amateau and McCarthy, 2004). Indeed, the masculinizing effects of $\mathrm{PGE}_{2}$ are so potent that a single exposure on the day of birth is sufficient to masculinize dendritic spine density and adult sexual behavior (Wright and McCarthy, 2009). The short half-life of $\mathrm{PGE}_{2}$ suggests that feedforward mechanisms in the POA lead to sustained production of prostaglandins over the critical period for sexual differentiation. Microglia both 
express prostaglandin receptors and produce prostaglandins (Minghetti et al., 1997; Minghetti and Levi, 1998) and are also responsive to estrogens (Morale et al., 2006), leading us to hypothesize that they mediate the feedforward process through which $\mathrm{PGE}_{2}$ begets more $\mathrm{PGE}_{2}$ in the POA.

\section{Materials and Methods}

Animals. All breeding and experimental procedures were approved by the Institutional Care and Use Committee at University of Maryland Baltimore and performed in accordance with national animal care and use guidelines. Adult Sprague Dawley rats (Harlan) were mated in our facility, or timed pregnant animals ordered to deliver within a week of arrival at the animal facility (Harlan). Animals were maintained on a 12:12 h reverse light/dark cycle, with ad libitum food and water. Pregnant dams were allowed to deliver naturally. On the day of birth (postnatal day 0 [PN0]), pups were sexed and treated within $6 \mathrm{~h}$ of detection in the nest.

In vivo manipulations. Bilateral intracerebroventricular (i.c.v.) injections were performed under cryoanesthesia. A 23 gauge $1 \mu$ l of Hamilton syringe attached to a stereotaxic manipulator was placed $1 \mathrm{~mm}$ caudal to bregma and $1 \mathrm{~mm}$ lateral to the midline, lowered $3.0 \mathrm{~mm}$ into the brain, and then backed out $1 \mathrm{~mm}$. A total of $1 \mu \mathrm{l}$ of drug or vehicle was infused over $60 \mathrm{~s}$, and the procedure repeated on the other hemisphere. Subcutaneous hormone injections were performed at a volume of $0.1 \mathrm{ml}$ on the dorsal surface of the pup and the injection site sealed with VetBond (3M) to prevent drug leakage. For all procedures, the separation of pups from the dam was kept to a minimum, with subcutaneously injected animals being separated for $<15 \mathrm{~min}$, and intracerebroventricular-injected animals being separated for $\sim 1 \mathrm{~h}$. The drug doses and timing of dosing specified below were all based on those shown previously to be effective in the neonatal POA (Wright and McCarthy, 2009).

Surgery. After neonatal treatment, animals used for behavioral testing were weaned at PN21 into sex-specific groups of three. At PN50, animals were gonadectomized under isoflurane anesthesia and implanted with a SILASTIC capsule containing crystalline testosterone $(1.58 \mathrm{~mm}$ inner diameter, $3.18 \mathrm{~mm}$ outer diameter; $30 \mathrm{~mm}$ length), producing adult levels of testosterone (Amateau and McCarthy, 2004). Animals were allowed to recover for 2 weeks before behavioral testing. Age-matched stimulus females were also gonadectomized before hormonal priming and behavioral testing.

Behavioral testing. At $\sim$ PN65, animals were tested for male copulatory behavior. Animals received a weekly $30 \mathrm{~min}$ copulatory behavior test for three consecutive weeks during the dark phase of the light cycle and under red-light illumination. Testing began with the addition to the arena of a hormonally primed receptive female given $10 \mu \mathrm{g}$ of estradiol benzoate in $0.1 \mathrm{ml}$ of sesame oil subcutaneously 1 and $2 \mathrm{~d}$ before testing, and $500 \mu \mathrm{g}$ of progesterone in $0.1 \mathrm{ml}$ of oil subcutaneously $4 \mathrm{~h}$ before testing. Behavioral testing was videotaped and frequencies of mounts and intromission-like behaviors and latencies to first mount and first intromission-like behavior were quantified with experimenters blind to condition. A mount was counted when the subject placed both forepaws on the haunches of the stimulus female and thrust against her. An intromission-like behavior was counted only when the subject made pelvic contact with the genitals of the stimulus female by quickly shifting his weight, engaging in extreme flexion of the haunches, and then reflexively disengaging. If animals failed to mount or intromit in a given session, their latency was set at the maximum testing time (1800 s). The mean latency to mount, mean latency to intromission-like behavior, mean number of mounts, and mean number of intromission-like behaviors were generated by averaging across all three trials.

Brain collection and immunohistochemistry. For immunohistochemistry experiments, animals were deeply anesthetized with FatalPlus (Vortech Pharmaceuticals), transcardially perfused with $0.1 \mathrm{~m}$ PBS followed by $4 \%$ paraformaldehyde, their brains removed and postfixed overnight in $4 \%$ paraformaldehyde, and cryoprotected with $30 \%$ sucrose until they sank. Brains were coronally sectioned on a cryostat into three alternate series at a thickness of $45 \mu \mathrm{m}$. Free-floating sections from one alternate series underwent immunohistochemical staining for the microglial/ macrophage specific marker, ionized calcium binding adaptor molecule
1 (Iba1; Wako Chemicals). Sections were extensively rinsed with PBS, blocked for $1 \mathrm{~h}$ with $10 \%$ normal goat serum (NGS) in PBS $+0.4 \%$ Triton- $\mathrm{X}$, and endogenous peroxidase activity removed by incubation in $0.3 \% \mathrm{H}_{2} \mathrm{O}_{2}$ in $50 \%$ methanol. Sections were then rinsed and incubated overnight at $4^{\circ} \mathrm{C}$ in antiserum to Ibal (1:1000) in PBS $+5 \%$ NGS $+0.4 \%$ Triton-X. On $\mathrm{d} 2$, sections were then rinsed and incubated for $1 \mathrm{~h}$ at room temperature with biotinylated anti-rabbit secondary antibody (1:500; Vector Laboratories) in PBS $+0.4 \%$ Triton-X $+2.5 \%$ NGS, followed by $1 \mathrm{~h}$ in $\mathrm{ABC}$ complex (1:500 each; Vector Laboratories) in PBS $+0.4 \%$ Triton-X. A 10 min incubation with Ni-DAB chromogen visualized the reaction product $(2.5 \% \mathrm{Ni}, 0.05 \% 3,3$ diaminobenzidine tetrachloride, $0.005 \% \mathrm{H}_{2} \mathrm{O}_{2}$ in $0.175 \mathrm{M}$ sodium acetate). Sections were then thoroughly rinsed in PBS, mounted on gelatin-subbed slides, cleared with ascending alcohol, defatted with xylenes, and coverslipped with DPX mounting medium.

To further characterize activated microglia, immunofluorescent staining was performed in the POA for standard markers for classical (M1) microglial activation (IL-1 $\beta$ and TNF $\alpha$ ) and alternative (M2) microglial activation (arginase-1 and the mannose receptor, CD206) along with Ibal. After sectioning as described above, POA sections were incubated with 50\% methanol for $15 \mathrm{~min}$, blocked for $1 \mathrm{~h}$ with $10 \%$ NGS in PBS + $0.4 \%$ Triton- $\mathrm{X}$, and then incubated overnight at $4^{\circ} \mathrm{C}$ in antiserum to Iba 1 (1:1000) and either IL-1 $\beta$ (M1 marker; R\&D Systems, mouse), TNF $\alpha$ (M1 marker; Abcam, mouse), arginase-1 (M2 marker; Santa Cruz Biotechnology, mouse), or CD206 (M2 marker; Santa Cruz Biotechnology, goat), all 1:1000 in PBS $+5 \%$ NGS $+0.4 \%$ Triton-X. Sections were subsequently rinsed, incubated for $2 \mathrm{~h}$ in appropriate donkey secondary antibodies conjugated to AlexaFluor-594 (Invitrogen, 1:200) and 488 (Invitrogen, 1:333) in PBS $+5 \%$ NGS $+0.4 \%$ Triton-X, rinsed extensively, mounted, and coverslipped with VectaShield Hard Set with DAPI mounting medium (Vector Laboratories). Sections were then imaged using a Zeiss LSM5 Duo, a 40× oil objective and acquired using Zen 2009 software to determine colabeling between Iba1 and the M1 or M2 markers.

To determine whether microglia have estrogen receptors, fluorescent staining was performed in the POA of male and female pups for FITClabeled tomato lectin, which robustly labels microglia, along with immunofluorescent staining for estrogen receptor $\alpha$. After sectioning as described above, POA sections were incubated with 50\% methanol for 15 min, blocked for $1 \mathrm{~h}$ with $10 \%$ NGS in PBS $+0.4 \%$ Triton-X, and then incubated for $72 \mathrm{~h}$ at $4^{\circ} \mathrm{C}$ in antiserum to estrogen receptor $\alpha$ (Millipore, rabbit; $1: 10000)$ in PBS $+5 \%$ NGS $+0.4 \%$ Triton-X. Sections were subsequently rinsed, incubated for $2 \mathrm{~h}$ in donkey anti-rabbit conjugated to AlexaFluor-594 (Invitrogen, 1:200) along with FITC-conjugated tomato lectin ( $5 \mu \mathrm{g} / \mathrm{ml}$; Sigma) in PBS $+5 \%$ NGS $+0.4 \%$ Triton-X, rinsed extensively, mounted, and coverslipped with VectaShield Hard Set mounting medium (Vector Laboratories). Sections were then imaged as above using a Zeiss LSM5 Duo confocal microscope.

Stereological cell counts. Stereological cell counts were performed across the POA using computer-based stereology software (StereoInvestigator, Microbrightfield) interfaced with a Nikon Eclipse E600 microscope and an MBF Bioscience CX9000 Digital Camera. One of three alternate series was chosen for stereological cell counts, and all sections in that series containing the POA were counted ( 4 or 5 sections). The physical fractionator method was used to count cells, using a $150 \mu \mathrm{m} \times 150$ $\mu \mathrm{m}$ counting frame at $40 \times$ magnification, sampling every $300 \mu \mathrm{m}^{2}$ across the POA. Although microglial cells are sufficiently small that it is unlikely a single cell would be visible in consecutive sections in an alternate series, cells that did not have a complete, darkly labeled cell body were not counted. Microglial cells were also characterized morphologically to determine whether there were group differences in the microglial activation profile. Microglial morphology can be qualitatively characterized on the basis of morphology (Schafer et al., 2012; Schwarz et al., 2012). Quiescent microglia show a ramified morphology with long, thin, branched processes; transitioning microglia show short, thick, processes; activated microglia show enlarged cell bodies and a characteristic round, ameboid morphology (Kloss et al., 2001; Stence et al., 2001; Schafer et al., 2012; Schwarz et al., 2012). During stereological cell counts, each counted cell was characterized as ramified, transitioning, or activated (Fig. 1 for ex- 

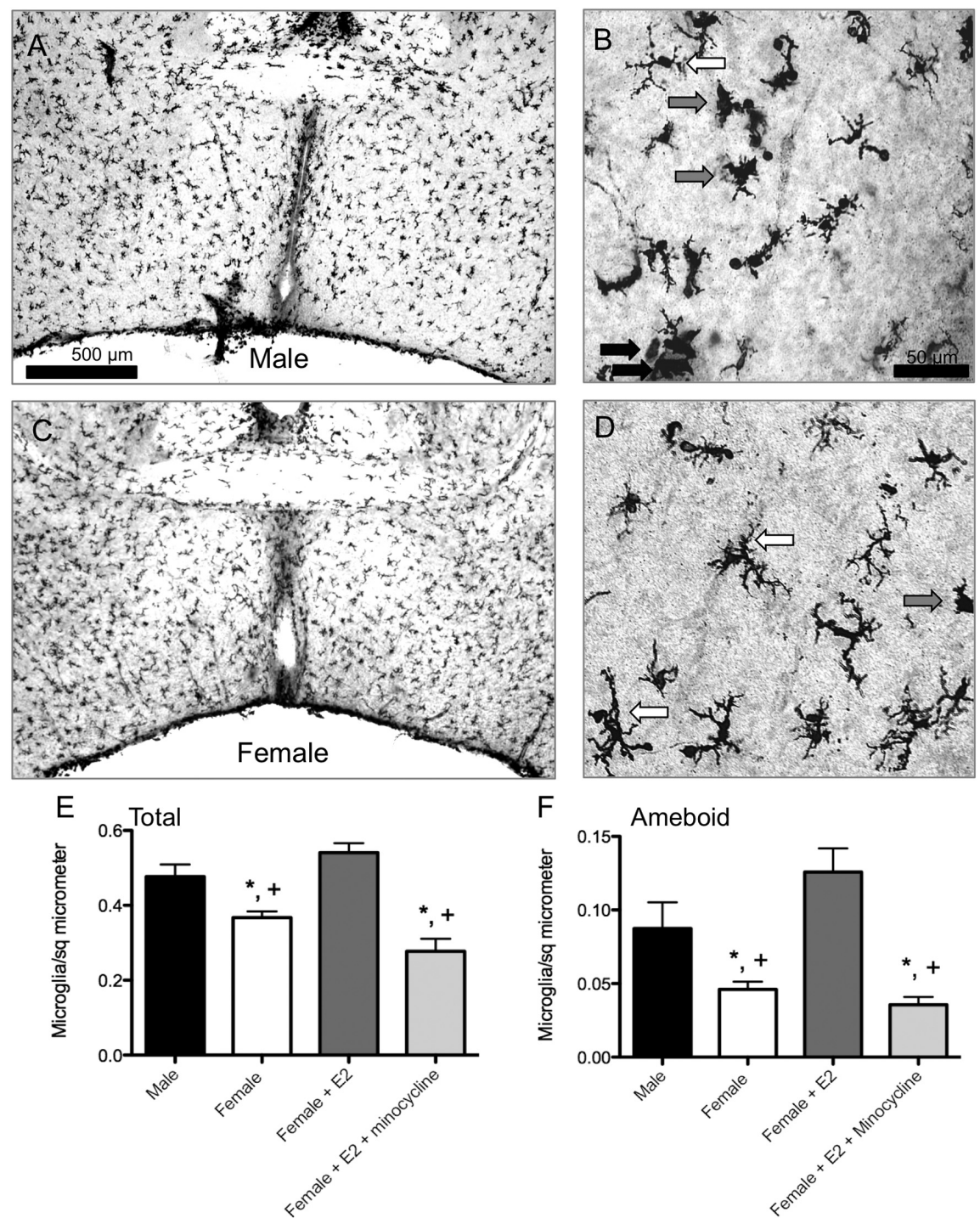

$\mathrm{F}$
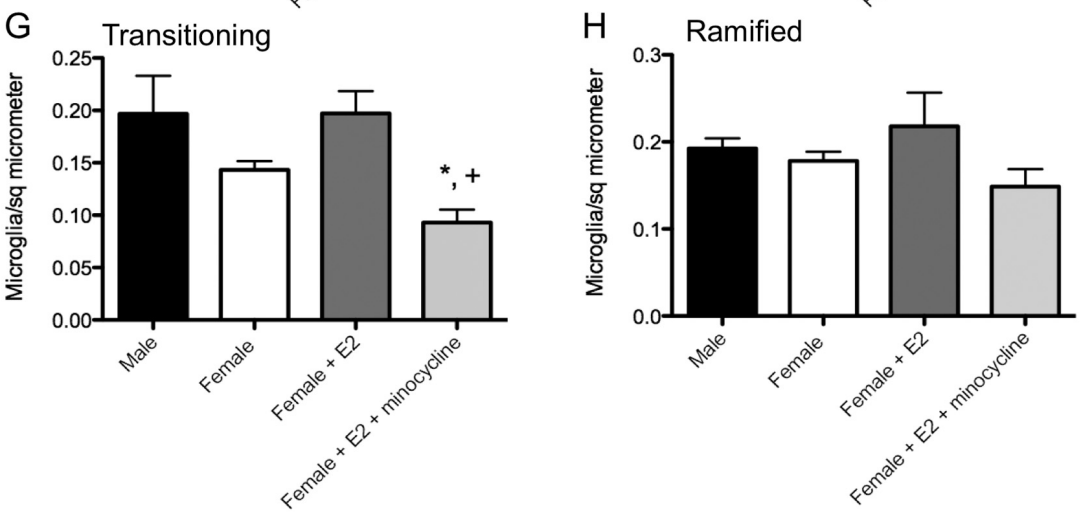

Figure 1. Sex differences and hormonal dependence of microglia in the POA. Iba1 staining in the POA on postnatal day 2 of a male pup $(\boldsymbol{A}, \boldsymbol{B})$ and a female pup $(\boldsymbol{C}, \boldsymbol{D})$ at $4 \times$ magnification and $20 \times$ magnification. Scale bar: $\boldsymbol{A}, \boldsymbol{B}, 500 \mu \mathrm{m} ; \boldsymbol{C}, \boldsymbol{D}, 50 \mu \mathrm{m}$. Black arrows indicate examples of ameboid microglia; gray arrows indicate examples of transitioning microglia; white arrows indicate examples of ramified microglia. Males had significantly more total microglia $(\boldsymbol{E})$ and ameboid microglia specifically $(\boldsymbol{F})$ in the POA on PN2 than females. Estradiol masculinized microglial counts in females, and cotreatment of females with estradiol and minocycline prevented this masculinization. Among transitioning microglia, females cotreated with minocycline and estradiol had significantly fewer cells than males or estradiol-treated females $(\boldsymbol{G})$. ${ }^{*}$ Significantly different from males (ANOVA: $p<0.05$ ). ${ }^{+}$Significantly different from females $+\mathrm{E}_{2}$ (ANOVA: $p<0.05$ ). There was no sex difference or hormonal dependence on the number of ramified microglia $(\boldsymbol{H})$. amples). The overall area of the POA sampled was calculated, and the estimated microglial population for each animal was expressed as a density measurement (microglia/ $\mu \mathrm{m}^{2}$ ).

$3 D$ reconstruction of microglia. To further assess the morphological profile of microglia across groups, a sampling of microglia was reconstructed in three dimensions using a Nikon Eclipse E600 microscope and an MBF Bioscience CX9000 Digital Camera coupled to a computer-based morphometry system (Neurolucida, MicroBrightField). The borders of the POA were outlined, and a standardized counting field $(200 \times 200 \mu \mathrm{m})$ was randomly placed within the POA. All Iba1-positive cells within that field were reconstructed using a $60 \times$ objective. Data collected included cell body size, process length, number of processes, and number of process nodes. These measures were averaged across a given animal for all cells. Experimenters were blind to condition during image acquisition, reconstruction, and analysis.

Microdissection of POA. For Western blot or immunoassay experiments, pups were killed by rapid decapitation $24 \mathrm{~h}$ after final drug treatment, their brains removed and placed in a Zivic Miller brain block, dorsal surface down. A $1 \mathrm{~mm}$ coronal section of the brain was taken using the rostral and caudal boundaries of the optic chiasm as landmarks. The anterior commissure served as the dorsal boundary of the POA. The isolated POA tissue was flash frozen on dry ice and stored at $-80^{\circ} \mathrm{C}$.

Western blot. Tissue was homogenized in RIPA buffer containing 1\% Igepal CA630, $0.25 \%$ deoxycholic acid, $1 \mathrm{~mm}$ EDTA, 154 $\mathrm{mm} \mathrm{NaCl}$, and $65 \mathrm{~mm}$ Trizma Base, with added protease and phosphatase inhibitors (1:1000). All chemicals were obtained from Sigma unless otherwise specified. Protein supernatant was extracted after $10 \mathrm{~min}$ of centrifugation at $3000 \mathrm{rpm}$ at $4^{\circ} \mathrm{C}$, and total protein concentration determined via Bradford assay. Ten micrograms protein per sample was loaded and electrophoresed on an $8-16 \%$ precast SDS polyacrylamide gel (Invitrogen) and transferred onto a single PVDF membrane (Bio-Rad) per experiment. Membranes were blocked for $60 \mathrm{~min}$ in 5\% nonfat milk in $0.1 \%$ Tween in Tris-buffered saline (TTBS). Membranes were subsequently incubated with primary antisera in 5\% milk in TTBS overnight at $4^{\circ} \mathrm{C}$. Antisera were used at the following concentrations: spinophilin (Millipore, 1:1000) and Iba1 (Abcam, 1:500). Membranes were rinsed, and appropriate HRP-conjugated secondary antibodies were applied in 5\% milk in TTBS for $30 \mathrm{~min}$. A Phototype chemiluminescence system (New England Biolabs) was used to detect the immunoblots by exposing the membrane to Hyperfield ECL (GE Healthcare). Integrative grayscale pixel area densitometry captured with a CCD camera was quantified with NIH Image software. Ponceau staining, which incorporates the signal from $>200$ proteins in the dominant band, was used as a loading control as described previously (Olesen and 
Auger, 2005) and final immunoblot densitometry values for each lane expressed as a percentage of Ponceau staining for the same lane.

Enzyme immunoassay. Tissue was homogenized in RIPA buffer containing 1\% Igepal CA630, 0.25\% deoxycholic acid, 1 mM EDTA, $154 \mathrm{~mm}$ $\mathrm{NaCl}$, and $65 \mathrm{~mm}$ Trizma Base, with added protease and phosphatase inhibitors (1:1000). Protein supernatant was extracted after $10 \mathrm{~min}$ of centrifugation at $3000 \mathrm{rpm}$ at $4^{\circ} \mathrm{C}$, and total protein concentration determined via Bradford assay. For each sample $150 \mu \mathrm{l}$ of was loaded into a C18 reverse phase column (200 mg of bed weight; Thermo Scientific), and lipid extracted by consecutive washes with $\mathrm{dH}_{2} \mathrm{O}, 15 \%$ ethanol, and hexane, followed by sample elution in ethyl acetate. Once ethyl acetate had evaporated, samples were reconstituted in assay buffer and an enzyme immunoassay run for $\mathrm{PGE}_{2}$ (high sensitivity $\mathrm{PGE}_{2}$ Kit K019-HX, Arbor Assays), with all samples and standards run in triplicate. Sample values were interpolated from a 6 point standard curve, corrected for total protein concentration, and expressed as picograms of $\mathrm{PGE}_{2}$ per milligram of total protein.

POA primary culture. On PN0, the POA from female pups ( $n=6-10)$ was microdissected as described as above, placed into $2 \mathrm{ml}$ of HBSS, and digested with $300 \mu \mathrm{l}$ of $0.25 \%$ trypsin (Invitrogen) and $250 \mu \mathrm{l}$ of $1 \%$ DNASE for $15 \mathrm{~min}$ at $37^{\circ} \mathrm{C}$. The supernatant was removed, and cells were washed twice with HBSS. Cells were then gently triterated with a Pasteur pipette in plating media consisting of DMEM/F12 medium without phenol red (Invitrogen), 5\% FBS (Invitrogen), and 1\% antibiotic/antimycotic (Invitrogen) until dissociated. Cell density and viability were determined on a hemacytometer using Trypan blue, and cells plated at $500,000 \mathrm{cells} / \mathrm{slip}$ in a $100 \mu \mathrm{l}$ volume on 2.5 -cm-round poly-lysinetreated glass coverslips in $3.5 \mathrm{~cm}$ Petri dishes. After allowing cells to seed for $2 \mathrm{~h}$, cultures were fed with $2 \mathrm{ml}$ of cell culture medium, consisting of Neurobasal A Medium without phenol red (Invitrogen), 1\% antibiotic/ antimycotic (Invitrogen), 1\% B27 supplement (Invitrogen), and 0.125\% L-glutamine (Sigma), and allowed to acclimate and grow for $24 \mathrm{~h}$ before treatment.

Microglia-free POA cultures. After preparation of POA primary cultures as described above, on $1 \mathrm{~d}$ in vitro (DIV1) cultures were depleted of microglia via agitation. Coverslips were shaken at 200 RPM for $30 \mathrm{~min}$ to detach microglia, after which the microglia-containing medium was replaced with fresh culture medium, and cultures treated as appropriate for the experiment.

Cell culture immunohistochemistry. Cells were fixed with $4 \%$ paraformaldehyde in PBS for $10 \mathrm{~min}$, rinsed 3 times with PBS, permeabilized for 30 min with $50 \%$ ethanol, blocked for $1 \mathrm{~h}$ with $5 \%$ NGS in PBS $+0.4 \%$ Triton-X, and incubated overnight at $4^{\circ} \mathrm{C}$ in antiserum to MAP2 (1:1000 mouse monoclonal, Sigma), GFAP (1:5000 mouse monoclonal, Sigma), or Ibal (1:1000 rabbit polyclonal, Wako) in PBS $+2.5 \%$ NGS $+0.4 \%$ Triton-X. On d 2, coverslips were rinsed and incubated for $1 \mathrm{~h}$ at room temperature with appropriate biotinylated secondary antibodies (1:500; Vector Laboratories) in PBS $+0.4 \%$ Triton-X $+2.5 \%$ NGS, followed by $1 \mathrm{~h}$ in ABC complex (1:500 each; Vector Laboratories) in PBS. A $10 \mathrm{~min}$ incubation with $\mathrm{Ni}-\mathrm{DAB}$ chromogen visualized the reaction product (2.5\% Ni, $0.05 \%, 3,3$ diaminobenzidine tetrachloride, $0.005 \% \mathrm{H}_{2} \mathrm{O}_{2}$ in $0.175 \mathrm{~m}$ sodium acetate). Coverslips were thoroughly rinsed in PBS, cleared with ascending alcohol, defatted with xylenes, and mounted with DPX mounting medium. MAP2 protein is not localized in dendritic spines but allows for accurate quantification of spine-like protrusions attributable to sufficient diffusion of the reaction product from the neurites into the spine-like protrusion in cultured neurons (Wright and McCarthy, 2009).

As with 3D cell reconstruction of microglia in intact tissue, a Nikon Eclipse E600 microscope and an MBF Bioscience CX9000 Digital Camera and Neurolucida software were used for cell culture image acquisition and analysis. For MAP2-labeled cells and single-cell reconstruction, cells were reconstructed using a $100 \times$ oil objective and were chosen for analysis if they had at least 2 distinct processes and uniform dark labeling throughout the extent of the cell. Data collected included cell body size, total neurite length, number of neurites, and number of spine-like protrusions from the neurite. Labeled protrusions of $<5 \mu \mathrm{m}$ in length from the neurite were counted as spine-like protrusions. For GFAP and Iba1labeled cultures, cell counts were performed using the physical fractiona- tor method of sampling across the coverslip as outlined above for POA brain sections. Experimenters were blind to condition during image acquisition, reconstruction, and analysis.

Data analysis. Data were analyzed using one-way ANOVA coupled with Newman-Keuls post hoc tests or planned Bonferonni post hoc comparisons ( $p$ value adjusted for multiple comparisons) when significant main effects were found.

Sex differences and hormonal dependence of microglial cell number and morphology in the POA. On PNO and PN1, female pups were either treated subcutaneously with estradiol benzoate in sesame oil $(100 \mu \mathrm{g} / 0.1$ $\mathrm{ml} ; n=5)$ or oil vehicle $(n=4)$; male pups were treated subcutaneously with oil vehicle $(n=4)$. An additional group was treated with estradiol and the microglial inhibitor, minocycline $\mathrm{HCl}(0.2 \mu \mathrm{g} / 0.2 \mu \mathrm{l}$ intracerebroventricularly; $n=5$ ) to determine whether minocycline effectively inhibited microglial activation and proliferation. We did not treat males with estradiol as they are the reference group for comparison and do not respond physiologically to exogenous estradiol. Pups were immediately returned to the dam after injection. On PN2, pups were transcardially perfused as detailed above, brains removed and processed for immunohistochemistry against the microglial marker, Ibal.

An alternate series in males and females were processed for double immunofluorescence against estrogen receptor $\alpha$ and FITC-labeled tomato lectin, which robustly labels microglia, to determine whether microglia in the POA are estrogen receptor-positive.

Immunological characterization of microglia in the POA. On PN0 and PN1, female pups were either treated subcutaneously with estradiol benzoate in sesame oil $(100 \mu \mathrm{g} / 0.1 \mathrm{ml} ; n=3)$ or oil vehicle $(n=3)$; male pups were treated subcutaneously with oil vehicle $(n=3)$. Pups were immediately returned to the dam after injection. On PN2, pups were transcardially perfused as detailed above, brains removed and processed for immunohistochemistry against the microglial marker, Ibal and either M1 markers (IL-1 $\beta$ or TNF $\alpha$ ) or the M2 markers (arginase-1 or CD206).

$P G E_{2}$ signaling and microglial cell number and morphology in the POA. On PN0 and PN1, female pups were treated intracerebroventricularly with $2.5 \mu \mathrm{g}$ of $\mathrm{PGE}_{2}$ (Sigma) in $0.9 \%$ saline $(n=4)$ or saline vehicle $(n=$ $4)$; all females were also treated subcutaneously with oil vehicle. Male pups were treated intracerebroventricularly with saline vehicle and subcutaneously with either the cyclooxygenase inhibitor, indomethacin (50 $\mu \mathrm{g} / 0.1 \mathrm{ml} ; n=4)$ or oil vehicle $(n=4)$. Animals were allowed to recover from cryoanesthesia under a heat lamp and returned to the dam. On PN2, pups were transcardially perfused, brains removed and processed for immunohistochemistry against the microglial marker, Ibal.

Estradiol and microglial regulation of dendritic spine proteins in vivo. On PN0 and PN1, female pups were treated subcutaneously with estradiol benzoate in sesame oil $(100 \mu \mathrm{g} / 0.1 \mathrm{ml} ; n=10)$ or oil vehicle $(n=10)$. In addition, pups were treated intracerebroventricularly with either saline vehicle or the microglial inhibitor, minocycline $\mathrm{HCl}(0.2 \mu \mathrm{g} / 0.2 \mu \mathrm{l})$. Three groups resulted: vehicle/vehicle females $(n=10)$, estradiol/vehicle females $(n=10)$, and estradiol/minocycline females $(n=8)$. Males from the same litters were used to validate that the chosen dose of minocycline was effective at decreasing Ibal protein. Males were either treated with intracerebroventricular saline vehicle $(n=3)$ or minocycline $(n=3)$. Animals were allowed to recover from cryoanesthesia under a heat lamp and returned to the dam. On PN2, pups were rapidly decapitated, POAs removed and rapidly frozen on dry ice to be used for Western blot analysis.

$\mathrm{PGE}_{2}$ and microglial regulation of dendritic spine proteins in vivo. On PN0 and PN1, female pups were either treated intracerebroventricularly with saline vehicle $(n=10), 2.5 \mu \mathrm{g}$ of $\mathrm{PGE}_{2}$ alone in $0.9 \%$ saline $(n=7)$, $0.2 \mu \mathrm{g}$ of minocycline $\mathrm{HCl}$ alone in saline $(n=5)$, or $2.5 \mu \mathrm{g}$ of $\mathrm{PGE}_{2}+$ $0.2 \mu \mathrm{g}$ of minocycline $\mathrm{HCl}$ in saline $(n=9)$. Animals were allowed to recover from cryoanesthesia under a heat lamp and returned to the dam. On PN3, pups were rapidly decapitated, POAs removed and rapidly frozen on dry ice to be used for Western blot analysis.

Estradiol and microglial regulation of dendritic spine-like protrusions in vitro. POA primary cultures were prepared from female pups on PN0 as outlined above. On DIV1 and DIV2, coverslips were treated with vehicle 

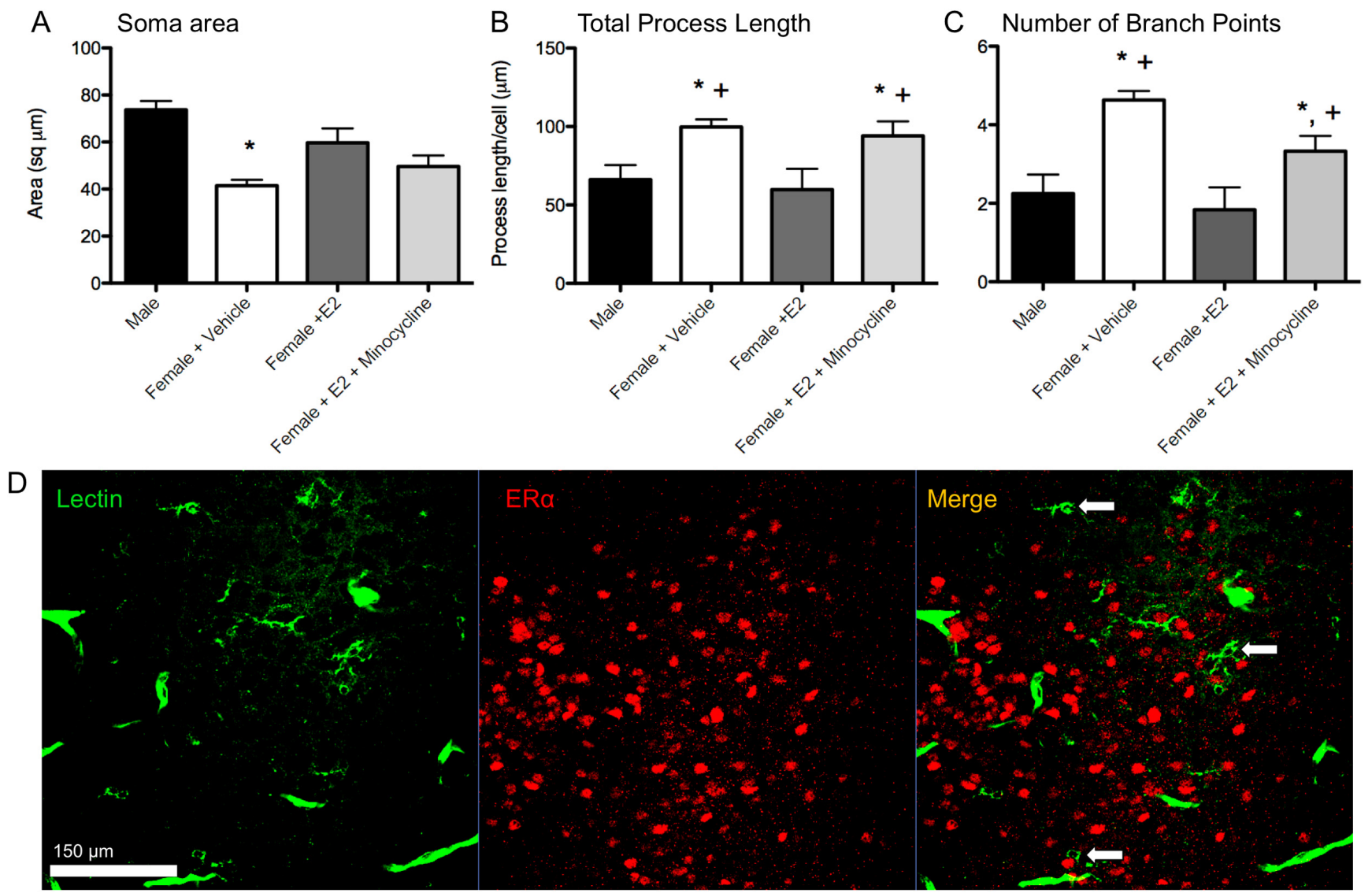

Figure 2. Three dimensional morphometric analysis of microglia $(\boldsymbol{A}-\boldsymbol{C})$. Males and estradiol-treated females had significantly larger microglial cell bodies $(\boldsymbol{A})$, shorter processes $(\boldsymbol{B})$, and fewer process branch points $(\boldsymbol{C})$ than vehicle-treated females in the POA on PN2. Cotreatment with estradiol and minocycline prevented estradiol's effects on process length and number of branch points. ${ }^{*}$ Significantly different from males (ANOVA: $p<0.05$ ). ${ }^{+}$Significantly different from females $+\mathrm{E}_{2}$ (ANOVA: $p<0.05$ ). D, Microglia in the neonatal P0A do not stain for estrogen receptor $\alpha$. Confocal imaging at $40 \times$ magnification of POA sections costained for tomato lectin (a pan-macrophage stain) and estrogen receptor $\alpha$ in males (pictured) and females show no colocalization. Scale bar, $150 \mu \mathrm{m}$. Arrows indicate examples of labeled microglia that are negative for estrogen receptor $\alpha$ staining.

$(n=7), 10 \mathrm{~nm}$ estradiol in DMSO $(n=5), 1 \mu \mathrm{M}$ minocyline $\mathrm{HCl}$ in PBS $(n=3)$, or $10 \mathrm{~nm}$ estradiol $+1 \mu \mathrm{M}$ minocycline $(n=6)$. A subset of cultures had microglia removed on DIV1 immediately before treatment and were then treated with estradiol $(n=5)$. On DIV3, cultures were fixed and stained immunohistochemically for MAP2 as outlined above, and cell body size, neurite number, neurite length, and number of spinelike protrusions were quantified on labeled neurons.

Microglial regulation of $\mathrm{PGE}_{2}$ production in the POA. On PN0 and PN1, female pups were treated subcutaneously with estradiol benzoate in sesame oil $(100 \mu \mathrm{g} / 0.1 \mathrm{ml})$ or oil vehicle; male pups were treated subcutaneously with oil vehicle $(n=10)$. In addition, pups were treated intracerebroventricularly with either saline vehicle or minocycline $(0.2$ $\mu \mathrm{g} / 0.2 \mu \mathrm{l})$. Four groups resulted: vehicle/vehicle males $(n=10)$, vehicle/ vehicle females $(n=13)$, estradiol/vehicle females $(n=11)$, and estradi$\mathrm{ol} /$ minocycline females $(n=16)$. On PN2, pups were rapidly decapitated, POAs were removed and rapidly frozen on dry ice to be used for enzyme immunoassay of $\mathrm{PGE}_{2}$ levels.

Microglial regulation of adult male sexual behavior. On PN0 and PN1, female pups were treated subcutaneously with estradiol benzoate in sesame oil $(100 \mu \mathrm{g} / 0.1 \mathrm{ml})$ or oil vehicle; male pups were treated subcutaneously with oil vehicle. In addition, pups were treated intracerebroventricularly with either saline vehicle or minocycline $(0.2 \mu \mathrm{g} / 0.2 \mu \mathrm{l})$. Four groups resulted: vehicle/vehicle males $(n=7)$, vehicle/vehicle females $(n=10)$, estradiol/vehicle females $(n=9)$, and estradiol/minocycline females $(n=12)$. Pups were returned to the dam, weaned at PN21, and raised to adulthood before gonadectomy and assessment of masculine sexual behavior as outlined above.

\section{Results}

Sex differences and hormonal dependence of microglial number and morphology in the POA

Female pups had significantly fewer microglia in the POA at PN2 than males. Estradiol treatment of females increased microglial counts to those of males and cotreating females with estradiol, and the microglial inhibitor minocycline prevented estradiol's masculinizing effect on overall microglial number $\left(F_{(3,14)}=\right.$ $17.79, p<0.0001$; Fig. $1 E)$. When overall cell counts were sorted on the basis of microglial morphology, female pups also had significantly fewer ameboid microglia in the POA at PN2 than males. Estradiol treatment of females increased microglial counts to those of males, and cotreating females with estradiol and minocycline prevented this increase $\left(F_{(3,14)}=13.16, p=0.0002\right.$; Fig. $1 F)$. Among transitioning microglia, females cotreated with minocycline and estradiol had significantly fewer cells than males or estradiol-treated females $\left(F_{(3,14)}=6.19 ; p=0.0067\right.$; Fig. $\left.1 G\right)$. There were no significant differences in the number of ramified microglia $\left(F_{(3,14)}=1.76 ; p=0.19\right.$; Fig. $\left.1 H\right)$. There were no differences in the area of the POA that was sampled across groups $\left(F_{(3,14)}=1.18 ; p=0.35\right)$.

Labeled microglia were also reconstructed in three dimensions to determine cell body size and number and length of processes in more detail. Microglia from vehicle-treated females had smaller cell bodies than males and estradiol-treated females 
$\left(F_{(3,13)}=9.20 ; p=0.002\right.$; Fig. $\left.2 A\right)$. Vehicle-treated females and females cotreated with estradiol and minocycline had both more process branch points $\left(F_{(3,13)}=7.89 ; p=0.003\right.$; Fig. $\left.2 B\right)$, and greater process length $\left(F_{(3,12)}=4.25 ; p=\right.$ 0.029; Fig. 2C) than males and females treated with estradiol, indicating a less activated morphological profile. There were no group differences in overall number of processes $\left(F_{(3,12)}=1.53 ; p=0.25\right)$ or number of cells analyzed $\left(F_{(3,13)}=1.25\right.$; $p=0.33)$.

Immunofluorescent colabeling of microglia and estrogen receptor $\alpha$ indicated no colocalization (Fig. 2D), suggesting that, in the neonatal POA, microglia do not express estrogen receptor $\alpha$. The presence of estrogen receptor $\beta$ was not assessed.

To determine the activational state of microglia in the neonatal POA, sections from males and females were colabeled with Ibal and either M1 markers (IL- $1 \beta$ or $\mathrm{TNF} \alpha$ ) or M2 markers (arginase-1 or the mannose receptor, CD206). Confocal analysis showed that all Iba1-positive cells in the POA were positive for IL- $1 \beta$ (Fig. $3 A$ ) and TNF $\alpha$ (Fig. 3B), both ameboid and ramified microglia. This was true for all groups, regardless of treatment or sex. In an alternate series of the same animals, all Iba1-positive cells were also positive for the M2 markers, arginase-1 (Fig. 3C) and CD206 (Fig. 3D), across all groups. Therefore, the ratio of M1:M2 markers throughout the POA was 1.00 across all groups.

\section{$\mathrm{PGE}_{2}$ regulates sex differences in microglial morphology}

Female pups once again had significantly fewer ameboid microglia in the POA at PN2 than males $\left(F_{(3,12)}=12.26, p=\right.$ 0.0006; Fig. 4B). $\mathrm{PGE}_{2}$ treatment of females increased ameboid microglial counts to those of vehicle males, and treatment of males with the COX inhibitor indomethacin decreased ameboid microglial counts to those of vehicle females. There was no overall effect of treatment with $\mathrm{PGE}_{2}$ on total microglial number $\left(F_{(3,12)}=3.07, p=0.069\right.$; Fig. $\left.4 A\right)$, although the pattern of the data matched that seen with ameboid microglia as well as total microglia in the experiment involving estradiol treatment, meaning that $\mathrm{PGE}_{2}$ tended to increase both. There were no significant differences in the number of ramified mi$\operatorname{croglia}\left(F_{(3,12)}=2.47 ; p=0.11\right.$; Fig. $\left.4 C\right)$ or transitioning microglia $\left(F_{(3,12)}=1.943 ; p=\right.$ $0.17)$. There were no differences in the area of the POA sampled across groups $\left(F_{(3,12)}=\right.$ $1.04 ; p=0.41)$.
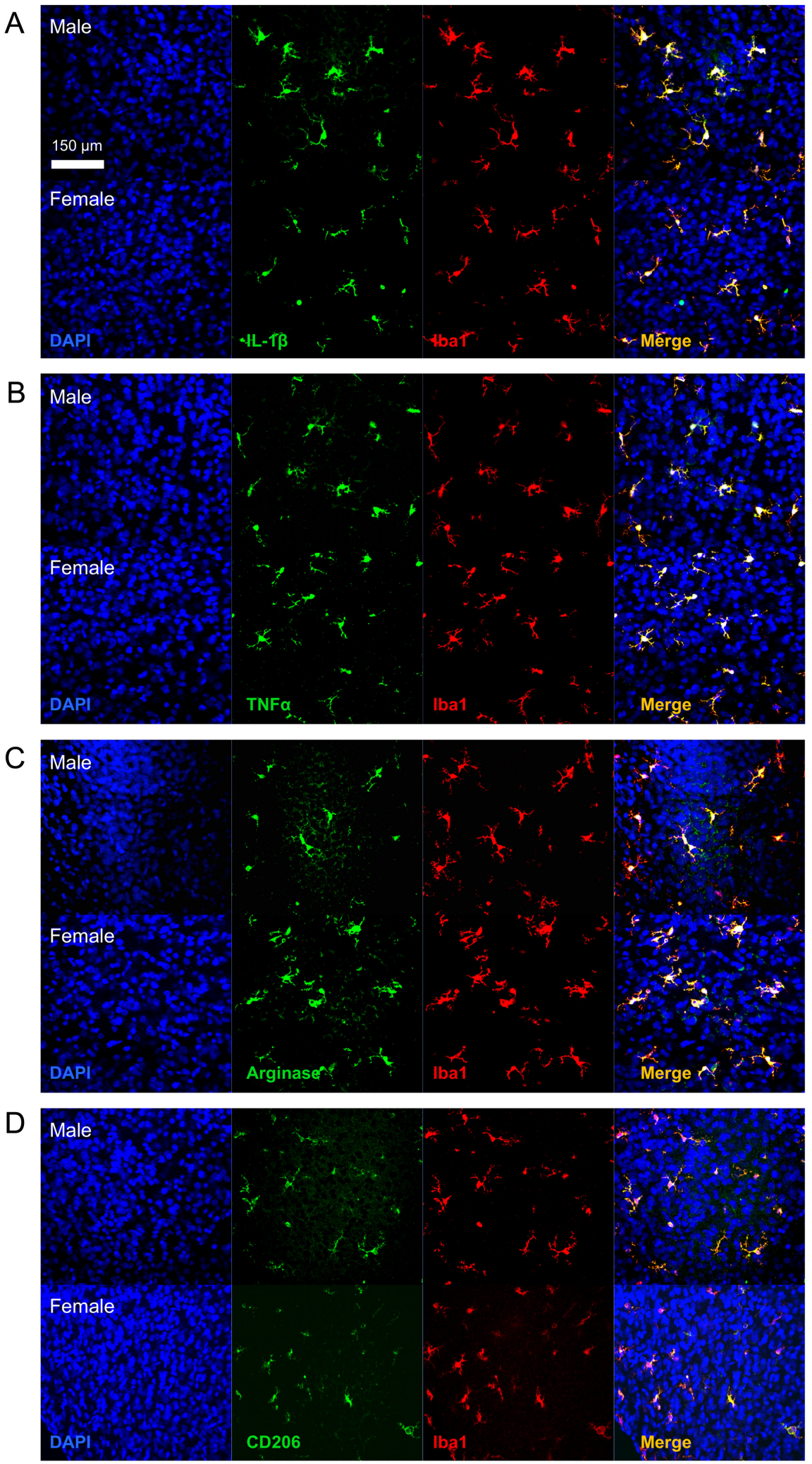

Figure 3. Microglia in the neonatal POA are positive for markers of classical (M1) and alternative (M2) microglial activation. A total of $100 \%$ of Iba1-stained microglia in males and females were positive for the $M 1$ marker interleukin $1 \beta(A)$, the M1 marker tumor necrosis factor $\alpha(\boldsymbol{B})$, the M2 marker arginase-1 (C), and the M2 marker CD206 (D). Confocal imaging performed at 40X magnification. Scale bar, $150 \mu \mathrm{m}$. 

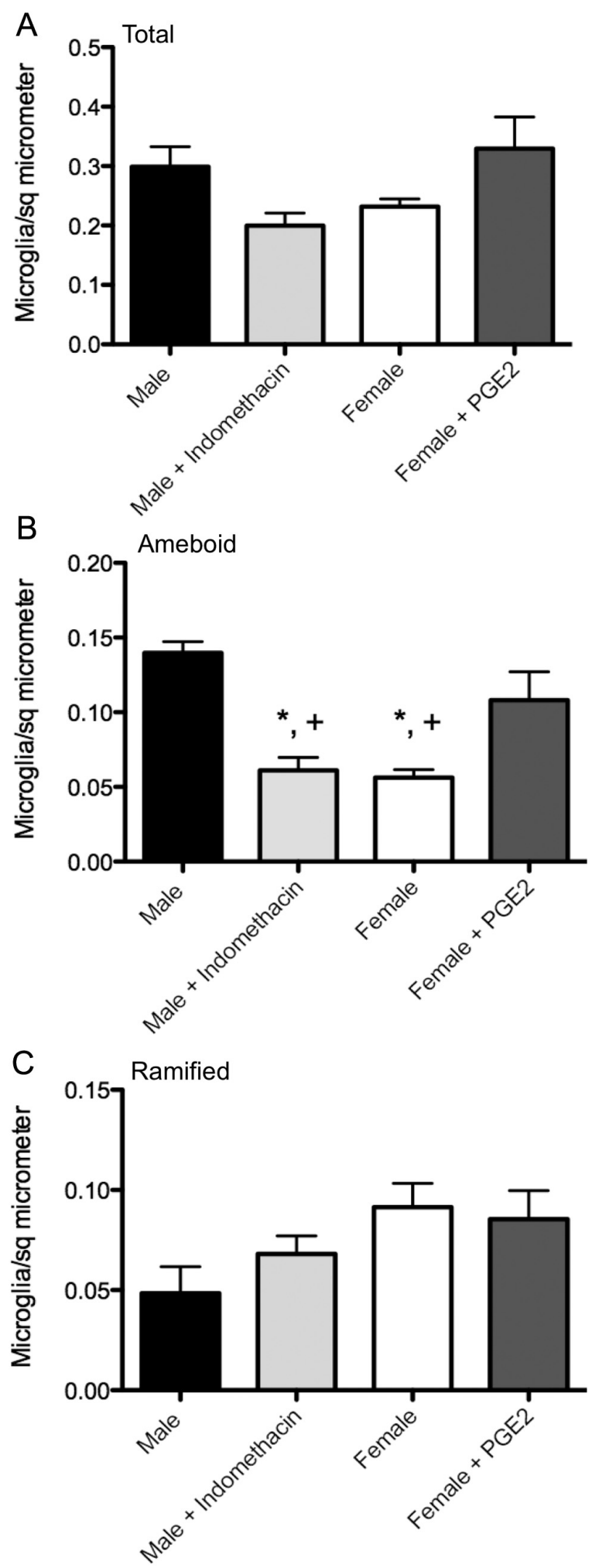

Figure 4. $P G E_{2}$ induces ameboid microglial morphology in the POA. $A$, Effects of $\mathrm{PGE}_{2}$ and the $C O X$ inhibitor, indomethacin, on total microglial counts in the POA. $B$, Effects of $\mathrm{PGE}_{2}$ and indomethacin on ameboid microglial counts in the POA. Males had significantly more ameboid microglia in the POA on PN2 than females. Indomethacin prevented masculinization of ameboid counts in males and $\mathrm{PGE}_{2}$ masculinized microglial counts in females. *Significantly different from vehicle males (ANOVA; $p<0.05$ ). ${ }^{+}$Significantly different from $\mathrm{PGE}_{2}$-treated females (ANOVA; $p<0.05$ ). There was no sex difference or prostaglandin dependence on ramified microglia (C).

Efficacy of minocycline

In addition to the microglial cell counts presented above, the efficacy of minocycline was further confirmed by treatment of newborn male pups on PNO and PN1, which significantly decreased Ibal protein expression in the POA, suggesting a downregulation of microglial activation $\left(t_{(4)}=3.72 ; p=0.02\right.$, Fig. $\left.5 A\right)$.

\section{Microglia contribute to masculinization of dendritic spine proteins in vivo}

Consistent with previous results from our laboratory, estradiol significantly increased spinophilin relative to vehicle controls; however, cotreatment of pups with estradiol and minocycline prevented that increase, maintaining spinophilin at the same as seen in vehicle-treated females $\left(F_{(2,25)}=4.26 ; p=0.026\right.$; Fig. $\left.5 B\right)$. $\mathrm{PGE}_{2}$ also increased spinophilin in females relative to vehicletreated females and cotreatment of pups with $\mathrm{PGE}_{2}$, and minocycline again prevented the increase, maintaining spinophilin at the level seen in control females $\left(F_{(3,27)}=3.92 ; p=0.019\right.$; Fig. $5 C)$. There was no effect of minocycline treatment itself on spinophilin levels (Fig. 5C).

\section{Microglia contribute to masculinization of spine-like protrusions in vitro}

The effectiveness of agitation to remove microglia from POA cultures was confirmed by an $80 \%$ reduction in microglial density, as measured by counting Ibal-positive cells in a subset of dishes (nonagitated + vehicle $=0.14$ cells $/ \mu \mathrm{m}$; agitated + vehicle $=0.021$ cells $/ \mu \mathrm{m}$; nonagitated + estradiol $=0.20$ cells $/ \mu \mathrm{m}$; agitated + estradiol $=0.051$ cells $/ \mu \mathrm{m}$; Fig. $6 C$ ).

Treatment with estradiol significantly increased the number of spine-like protrusions on neurites of cultured POA neurons relative to vehicle-treated controls $\left(F_{(4,21)}=14.59 ; p<0.0001\right.$; Fig. $6 B)$. Groups cotreated with estradiol and minocycline, minocycline alone, as well as microglia-depleted cultures treated with estradiol had significantly lower density of spine-like protrusions than estradiol-treated cultures containing microglia and were not significantly different from vehicle controls. There were no differences in soma size $\left(F_{(4,21)}=1.72 ; p=0.18\right)$, total neurite length per cell $\left(F_{(4,21)}=0.81 ; p=0.54\right)$, or number of neurites per cell $\left(F_{(4,21)}=0.58 ; p=0.68\right)$ across groups, consistent with our previous observations of selective effects of estradiol on spine-like protrusions.

To confirm that effects of microglial depletion on neurite spine-like protrusion density were not the result of coincident astroglial depletion, a subset of cultures were stained for the astrocytic marker, GFAP. We observed no differences in astrocyte density across treatment groups, as measured by counting GFAPpositive cells (nonagitated + vehicle $=0.045$ cells $/ \mu \mathrm{m}$; nonagitated + estradiol $=0.047 \mathrm{cells} / \mu \mathrm{m}$; agitated + estradiol $=0.058$ cells $/ \mu \mathrm{m})$.

\section{Microglial inhibition prevents estradiol-induced increases in $\mathrm{PGE}_{2}$}

Estradiol treatment of female pups for $2 \mathrm{~d}$ significantly increased $\mathrm{PGE}_{2}$ levels in the POA relative to controls, and cotreatment of pups with estradiol and minocycline generated $\mathrm{PGE}_{2}$ levels that were not different from control females $\left(F_{(2,46)}=3.02 ; p=0.039\right.$; Fig. 7), thus confirming that estradiol induction of $\mathrm{PGE}_{2}$ synthesis requires the presence of activated microglia.

Neonatal microglial inhibition prevents the estradiol-induced masculinization of adult sexual behavior in females

To determine whether the $\mathrm{PGE}_{2}$ produced by microglia in response to estradiol was functionally significant, we next treated 

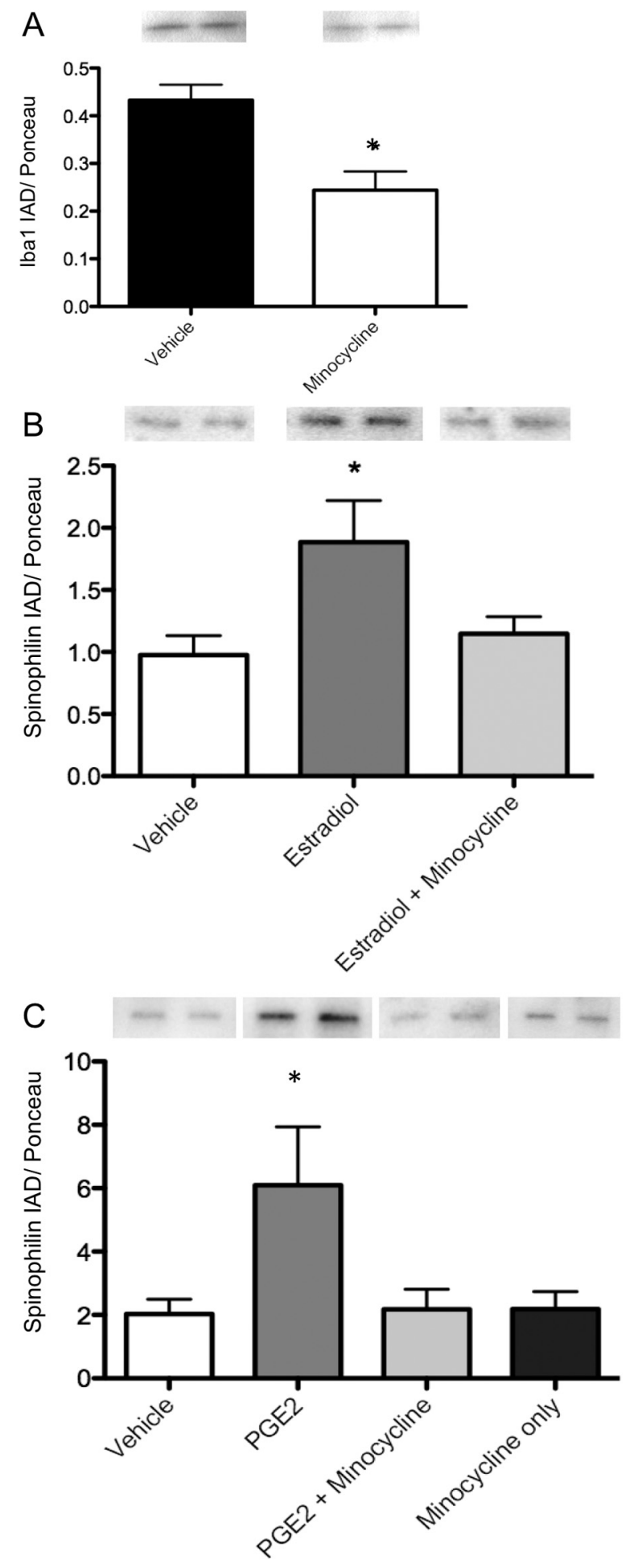

Figure 5. Effects of microglial inhibition on dendritic spine-related proteins in vivo. $\boldsymbol{A}$, The dose of minocycline used for all in vivo experiments ( $0.2 \mu$ gi.c.v.) significantly decreased levels of the microglial-associated protein Iba1 in the POA at PN2 relative to vehicle-treated controls. $\boldsymbol{B}$, Estradiol treatment on PN0 and PN1 in females increased levels of the spine-related protein spinophilin in the POA by PN2 relative to vehicle-treated control females; coadministration of minocycline with estradiol prevented that increase in spinophilin. $C, P_{2} E_{2}$ produced similar increases in spinophilin to estradiol, and coadministration of $\mathrm{PGE}_{2}$ and minocycline similarly prevented this increase. Minocycline administration alone had no effect on spinophilin levels. *Significantly different from vehicle (ANOVA; $p<0.05$ ). newborn female pups with estradiol plus minocycline and raised them to adulthood for behavioral analysis. All measures of masculine sexual behavior were significantly influenced by the neonatal treatments, including number of mounts $\left(F_{(3,33)}=4.32\right.$, $p=0.011)$, number of intromission-like behaviors $\left(F_{(3,33)}=\right.$ $76.83, p<0.0001)$, latency to mount $\left(F_{(3,33)}=3.966, p=0.016\right)$, and latency to intromit $\left(F_{(3,33)}=20.10, p<0.0001\right.$; Fig. 8). Specifically, with regard to mean number of mounts, there was a significant sex difference between males and control females, as expected, and treating females with estradiol increased the number of mounts to male levels, also as expected. However, cotreatment with estradiol and minocycline prevented the estradiol-induced masculinization of mount number in females (Fig. 8A).

Males showed significantly more intromission-like behaviors than any female group, in this study, most likely the result of the highly stringent criteria used (Fig. $8 B$ ). Because of this, we conducted a second analysis comparing only females and detected that estradiol-treated females exhibited a higher number of intromission-like behaviors relative to vehicle-treated females, as expected; however, cotreatment with estradiol and minocycline prevented the estradiol-induced masculinization of intromission-like behaviors in females $\left(F_{(2,28)}=7.44 ; p=0.0026\right.$; Fig. $8 B$, inset $)$.

The latency to first mount and intromission is often considered an indicator of sexual motivation. Males routinely exhibit faster mount latencies than females, and treating females with estradiol decreased latencies to male levels. However, cotreatment with estradiol and minocycline prevented the estradiolinduced masculinization of mount latency in females (Fig. 8C). The same pattern of results was observed for intromission latencies (Fig. 8D).

\section{Discussion}

It has been established for $>40$ years that steroid hormones masculinize the developing brain and promote expression of adult male sexual behavior. The surprising discovery that the inflammatory mediator, prostaglandin $\mathrm{E}_{2}$, is the critical signaling molecule that is both necessary and sufficient for masculinization (Amateau and McCarthy, 2002a, 2004) filled an important gap in our knowledge but also left many questions unanswered. Particularly difficult to explain was the observation that a single infusion of $\mathrm{PGE}_{2}$ into the brain of a neonatal female permanently masculinized her brain and behavior (Wright and McCarthy, 2009). The current results provide a plausible explanation by revealing a positive feedforward system that involves an additional cell type: microglia. We found prominent developmental sex differences in microglial number and morphology in the POA, and that these sex differences are programmed by neonatal exposure to gonadal hormones. Microglia express prostaglandin receptors and produce prostaglandins (Minghetti et al., 1997; Minghetti and Levi, 1998), which led us to investigate their role in the hypothesized feedforward process for $\mathrm{PGE}_{2}$ production in the POA. We have shown that inhibiting microglial activation prevents estradiol from increasing $\mathrm{PGE}_{2}$ levels in the POA. We have also shown that treating females with a masculinizing dose of $\mathrm{PGE}_{2}$ induces a male-like profile of activated microglia. Last, we demonstrated the essential importance of microglia to the process by pharmacologically inhibiting their activation during the critical period for brain sexual differentiation, which disrupted the masculinization of dendritic spine patterning and reproductive behavior in adulthood, even in the presence of a normally masculinizing dose of estradiol. Microglial inhibition prevented estradiol-induced masculinization of all sex behavior measures 

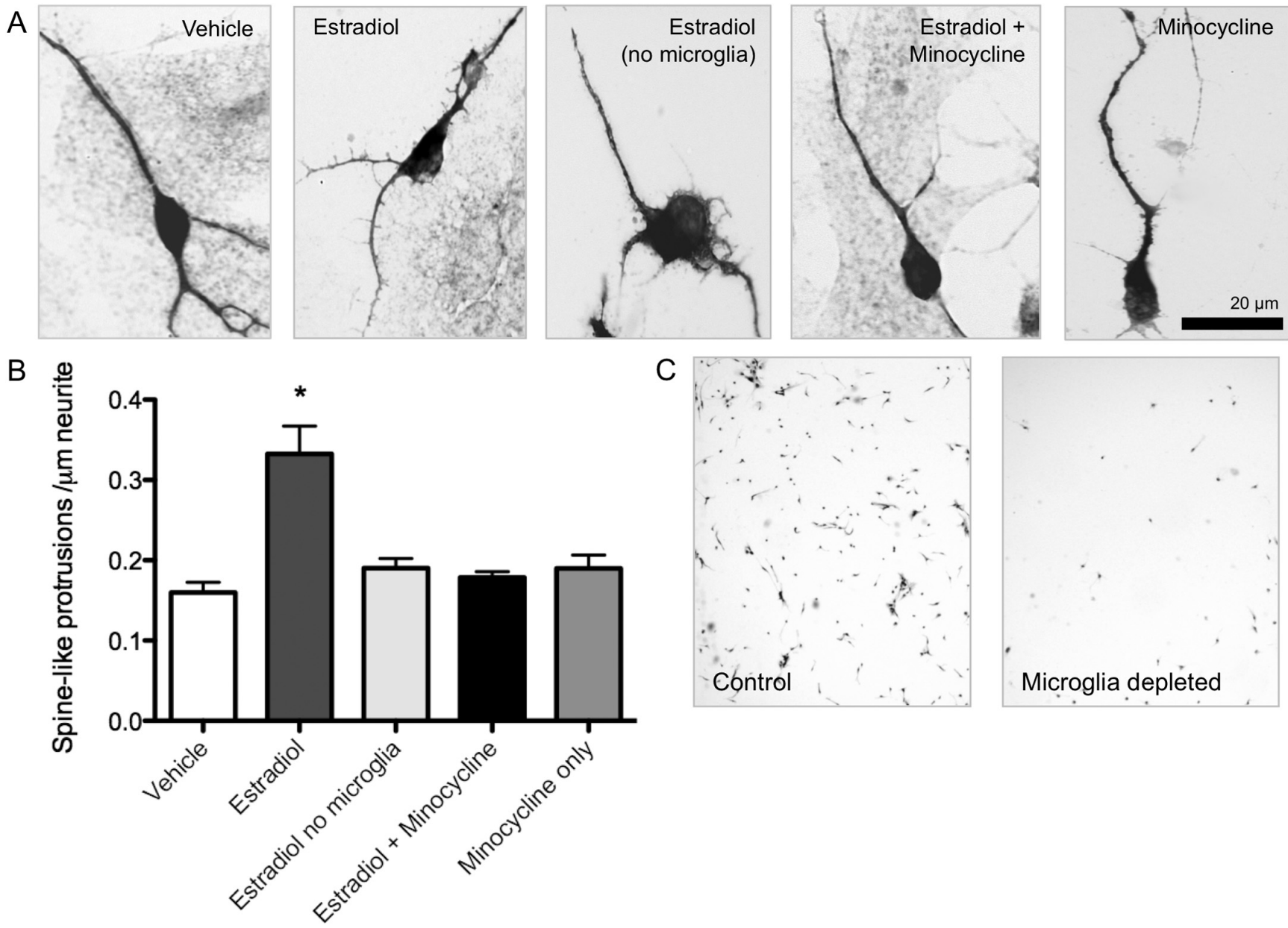

Figure 6. Effects of microglial inhibition on dendritic spine-related proteins in vitro. $A$, Representative images of MAP2 labeled neurons from primary POA cultures used to quantify dendritic spine-like protrusions at $100 \times$ magnification. Scale bar, $20 \mu \mathrm{m}$. B, Estradiol increased the density of spine-like protrusions relative to vehicle-treated controls. Estradioltreated cultures depleted of microglia did not show an increase in protrusions, nor did cultures cotreated with estradiol and minocycline. There was no change in spine density in cultures treated only with minocycline. * Significantly different from vehicle (ANOVA; $p<0.05$ ). C, lba1 staining in control cultures and cultures depleted of microglia. Depleted cultures had $\sim 80 \%$ fewer microglia.

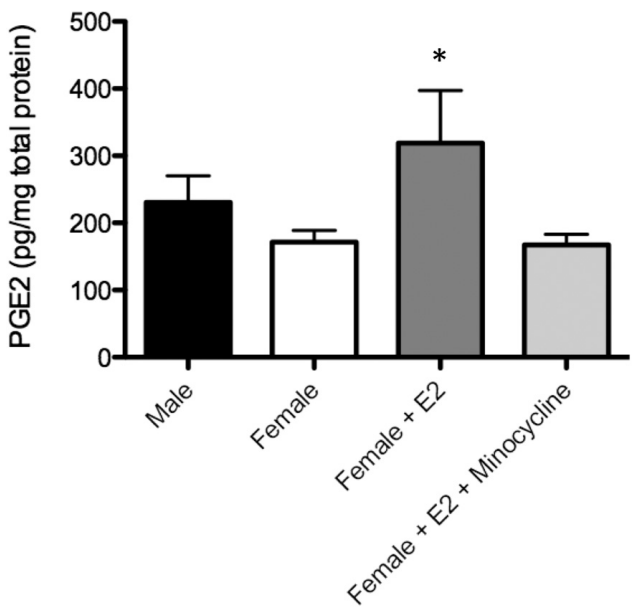

Figure 7. Effects of microglial inhibition on $\mathrm{PGE}_{2}$ levels in the $\mathrm{POA}$. Female pups treated with estradiol on PNO and PN1 showed a significant increase in PGE levels in the $P O A$ at PN2 relative to vehicle-treated females, and cotreatment with estradiol and minocycline prevented this increase. * Significantly different from vehicle female (ANOVA; $p<0.05)$ tested, both consummatory measures (number of mounts and intromission-like behaviors) as well as motivational measures (latencies to mount and intromit). Interestingly, recent work has shown that a key molecule in the production of normal male sex behavior is amyloid $\beta$ precursor protein (Park et al., 2010), a molecule known to induce microglial activation in the context of neurodegenerative disease (Meda et al., 1995). Therefore, the possibility that microglia and the immune system more generally are regulating the development of sex-specific behavior is worthy of further consideration

Microglia in the adult brain acquire an ameboid morphology in response to a variety of pathological states, including injury and neurodegenerative disease (e.g., Ling and Wong, 1993; Munn, 2000; Vargas et al., 2005) and activated microglia are a major source of proinflammatory molecules in the brain, including $\mathrm{PGE}_{2}$ (Minghetti et al., 1997; Minghetti and Levi, 1998). Microglia are more basally active in the normal neonatal brain (Ling et al., 1990; Wu et al., 1992; Ling and Wong, 1993; Dalmau et al., 1997; Schafer et al., 2012; Schwarz et al., 2012), suggesting that they are involved in more than response to brain injury or inflammation. After colonizing the neonatal brain, microglia transition from an ameboid morphology to the ramified, quiescent morphology seen in a healthy adult brain. Investigation into the role 
of microglia in normal brain development has begun to receive intense interest, and indeed microglia regulate a variety of normal developmental processes and physiological functions, including synapse elimination, spinogenesis and spine elimination, and the synaptic physiology of developing brain circuits (for review, see Tremblay et al., 2011). The current results expand this list by demonstrating a critical role for microglia in the sex-specific synaptic patterning of the POA that directly results from elevated estradiol in the male brain during a perinatal critical period. These results also expand the list of cell types involved in sexual differentiation. We have previously demonstrated that POA astrocytes are sexually differentiated by estradiol and likely contribute to the cellular cascades leading to dimorphic synaptic patterning (Amateau and McCarthy, 2002b). The addition of a critical role for microglia creates a cellular triumvirate, which rules over the developing male brain.

All (100\%) microglia in the developing POA were positive for markers of classical (M1) macrophage activation, IL-1 $\beta$ and TNF $\alpha$. The M1 phenotype is associated with the production of proinflammatory molecules, including prostaglandins; thus, this result is consistent with our finding that microglial inhibition reduced prostaglandin production. IL-1 $\beta$ and TNF $\alpha$ production by microglia is not only associated with the M1 phenotype (Mosser and Edwards, 2008), but these cytokines are also important for normal and even sex-specific brain development (Giulian et al., 1988; Krishnan et al., 2009). The fact that microglia in the developing brain were M1-positive underscores that proinflammatory molecules potentially serve a different, and beneficial, role in the developing brain, in contrast to their damaging roles in disease and injury states in the adult brain.

All (100\%) microglia were also positive for the alternative (M2) activation markers, arginase-1 and CD206. The results on CD206 are consistent with other literature showing that CD206 is abundant in the postnatal rodent brain (Burudi and RegnierVigouroux, 2001), particularly in the hypothalamus (Marzolo et al., 1999). The fact that cells were positive for both M1 and M2 markers likely reflects the immature state of microglia as they colonize the developing brain, and underscores that macrophages can show a spectrum of activation states (Mosser and Edwards, 2008). These results indicate that immature microglia in the neonatal brain may engage in complex signaling that serves both proinflammatory and anti-inflammatory functions. These results also suggest that our current characterization of ameboid microglia in the developing brain as "activated" in the adult or injured sense may not be entirely accurate, and that immature microglia are functionally distinct from activated microglia in adulthood, in keeping with their different roles in development and adulthood.

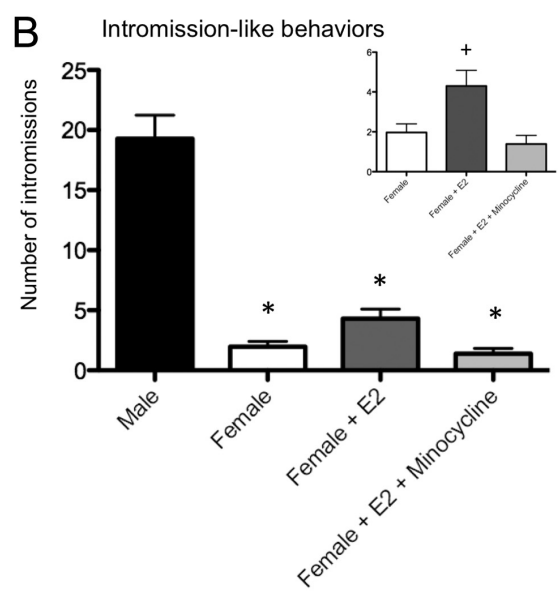

D Latency to Intromit

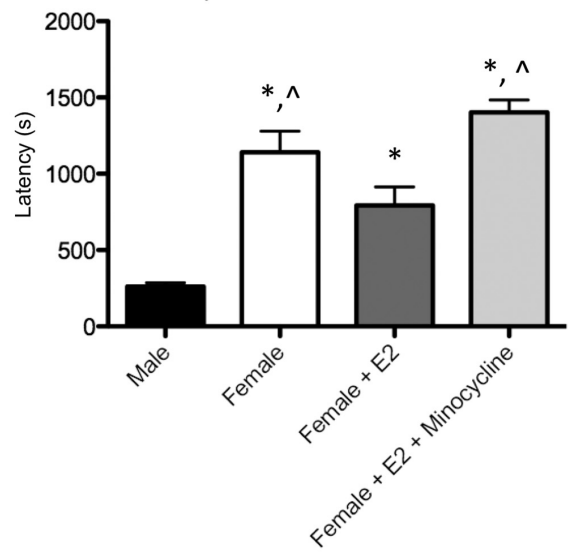

Figure 8. Effects of neonatal microglial inhibition on adult masculine sex behavior. $\boldsymbol{A}$, After adult gonadectomy and testoster-

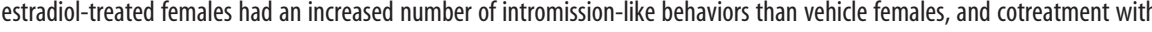
males; estradiol-treated females had decreased latencies relative to vehicle-treated females, and minocycline prevented estradiol-induced decreases in latency to intromit. *Significantly different from male $(p<0.05) .{ }^{+}$Significantly different from vehicle female $(p<0.05)$. ^Significantly different from estradiol-treated female $(p<0.05)$.

Several questions remain unanswered in this system, the first of which is as follows: what is (are) the primary cells of estradiol action? POA neurons express estrogen receptor at high density (Yokosuka et al., 1997; Orikasa et al., 2002), whereas astrocytes do not (Mong and McCarthy, 1999). Although microglia in other brain regions possess estrogen receptors (e.g., Vegeto et al., 2001), we did not detect estrogen receptor $\alpha$ in POA microglia. Microglial activation is regulated by estrogenic compounds in a variety of contexts (Vegeto et al., 2001; Saijo et al., 2011; Crain and Watters), and such effects can be mediated by estrogen receptor $\beta$ (Saijo et al., 2011), so our results do not preclude the possibility that estradiol is exerting direct effects on microglia in addition to indirect effects via $\mathrm{PGE}_{2}$. However, blocking $\mathrm{PGE}_{2}$ synthesis with the COX inhibitor indomethacin prevented the masculinized microglial phenotype in males, which further supports the hypothesis that $\mathrm{PGE}_{2}$, and not estradiol directly, leads to the masculine pattern of microglia.

A second question is the mechanism by which estradiol and/or $\mathrm{PGE}_{2}$ increases the ameboid morphology of microglia in males. The perinatal androgen surge and resultant high levels of estradiol may possibly extend the normal ameboid timeframe in 
males; therefore, treating a female with estradiol also extends the time course, but how this occurs is unknown. Estradiol in males may also increase microglial migration into the brain generally, promote recruitment into the preoptic area specifically, or promote microglial proliferation after initial colonization of the brain, or some combination thereof.

A third question is the specificity of the effects, both in terms of brain region and the pharmacological manipulations. That the effects are localized to the POA is confirmed by our ability to recapitulate the actions of minocycline on neurite spine-like protrusions in cultured POA neurons isolated from the rest of the brain. We also removed microglia from cultures and showed that estradiol no longer induced masculine levels of spines; thus, microglial involvement was confirmed without the use of minocycline, a tetracycline antibiotic with other potential effects on dendritic spine maturation in other rodent species, other brain regions, and at higher doses in vitro than used in this experiment (Bilousova et al., 2009). Moreover, in culture as well as in vivo, minocycline alone did not alter dendritic spine-like protrusions or spine protein levels from that of vehicles, once again suggesting that the minocycline dose used in these experiments did not nonspecifically alter dendritic spine density.

These studies investigated the interaction between the nervous, endocrine, and immune systems in the normal neonatal brain and found that microglial cells contribute to hormoneinduced development of a sexually differentiated brain and adult behavioral repertoire. More than 25\% of individuals will have some form of neurological or neuropsychiatric disease in their lives (World Health Organization, 2001), and sex is a major predictor of susceptibility to any given brain disorder. Male-biased disorders tend to be neurodevelopmental in origin and lifelong, whereas female-biased disorders tend to afflict adults in a more transient, though chronic, pattern. This dissociation suggests that the male brain may be particularly sensitive to developmental perturbations that lead to neurological disease, and underscores the importance of understanding the fundamental mechanisms of sex-specific brain development. Early life inflammation, either prenatal through maternal infection or postnatal, contributes to neurodevelopmental disturbances and abnormalities, including the risk of neuropsychiatric disorders (Nawa and Takei, 2006; Fatemi and Folsom, 2009). It is therefore essential to understand the mechanisms through which the immune system interacts with the endocrine and nervous systems to shape normal and aberrant brain development.

\section{References}

Amateau SK, McCarthy MM (2002a) A novel mechanism of dendritic spine plasticity involving estradiol induction of prostaglandin- $\mathrm{E}_{2}$. J Neurosci 22:8586-8596. Medline

Amateau SK, McCarthy MM (2002b) Sexual differentiation of astrocyte morphology in the developing rat preoptic area. J Neuroendocrinol 14: 904-910. CrossRef Medline

Amateau SK, McCarthy MM (2004) Induction of $\mathrm{PGE}_{2}$ by estradiol mediates developmental masculinization of sex behavior. Nat Neurosci 7:643650. CrossRef Medline

Bilousova TV, Dansie L, Ngo M, Aye J, Charles JR, Ethell DW, Ethell IM (2009) Minocycline promotes dendritic spine maturation and improves behavioural performance in the fragile X mouse model. J Med Genet 46:94-102. Medline

Burudi EM, Régnier-Vigouroux A (2001) Regional and cellular expression of the mannose receptor in the post-natal developing mouse brain. Cell Tissue Res 303:307-317. CrossRef Medline

Crain JM, Watters JJ (2010) Estrogen and P2 purinergic receptor systems in microglia: therapeutic targets for neuroprotection. Open Drug Discov J 2:148-167. Medline

Dalmau I, Finsen B, Tønder N, Zimmer J, González B, Castellano B (1997)
Development of microglia in the prenatal rat hippocampus. J Comp Neurol 377:70-84. CrossRef Medline

Davis EC, Popper P, Gorski RA (1996) The role of apoptosis in sexual differentiation of the rat sexually dimorphic nucleus of the preoptic area. Brain Res 734:10-18. CrossRef Medline

Fatemi SH, Folsom TD (2009) The neurodevelopmental hypothesis of schizophrenia, revisited. Schizophr Bull 35:528-548. CrossRef Medline

Gehrmann J, Matsumoto Y, Kreutzberg GW (1995) Microglia: intrinsic immuneffector cell of the brain. Brain Res Brain Res Rev 20:269-287. CrossRef Medline

Giulian D, Young DG, Woodward J, Brown DC, Lachman LB (1988) Interleukin-1 is an astroglial growth factor in the developing brain. J Neurosci 8:709-714. Medline

Gorski RA, Gordon JH, Shryne JE, Southam AM (1978) Evidence for a morphological sex difference within the medial preoptic area of the rat brain. Brain Res 148:333-346. CrossRef Medline

Kim OS, Lee CS, Kim HY, Joe EH, Jou I (2005) Characterization of new microglia-like cells obtained from neonatal rat brain. Biochem Biophys Res Commun 328:281-287. CrossRef Medline

Kingham PJ, Cuzner ML, Pocock JM (1999) Apoptotic pathways mobilized in microglia and neurones as a consequence of chromogranin A-induced microglial activation. J Neurochem 73:538-547. CrossRef Medline

Kloss CU, Bohatschek M, Kreutzberg GW, Raivich G (2001) Effect of lipopolysaccharide on the morphology and integrin immunoreactivity of ramified microglia in the mouse brain and in cell culture. Exp Neurol 168:32-46. CrossRef Medline

Krishnan S, Intlekofer KA, Aggison LK, Petersen SL (2009) Central role of TRAF-interacting protein in a new model of brain sexual differentiation. Proc Natl Acad Sci U S A 106:16692-16697. CrossRef Medline

Ling EA, Wong WC (1993) The origin and nature of ramified and amoeboid microglia: a historical review and current concepts. Glia 7:9-18. CrossRef Medline

Ling EA, Kaur LC, Yick TY, Wong WC (1990) Immunocytochemical localization of CR3 complement receptors with OX-42 in amoeboid microglia in postnatal rats. Anat Embryol (Berl) 182:481-486. CrossRef Medline

Mallat M, Marín-Teva JL, Chéret C (2005) Phagocytosis in the developing CNS: more than clearing the corpses. Curr Opin Neurobiol 15:101-107. CrossRef Medline

Marchetti B, Serra PA, L'Episcopo F, Tirolo C, Caniglia S, Testa N, Cioni S, Gennuso F, Rocchitta G, Desole MS, Mazzarino MC, Miele E, Morale MC (2005) Hormones are key actors in gene $X$ environment interactions programming the vulnerability to Parkinson's disease: glia as a common final pathway. Ann N Y Acad Sci 1057:296-318. CrossRef Medline

Marín-Teva JL, Dusart I, Colin C, Gervais A, van Rooijen N, Mallat M (2004) Microglia promote the death of developing Purkinje cells. Neuron 41: 535-547. CrossRef Medline

Marzolo MP, von Bernhardi R, Inestrosa NC (1999) Mannose receptor is present in a functional state in rat microglial cells. J Neurosci Res 58:387395. CrossRef Medline

McCarthy MM, Wright CL, Schwarz JM (2009) New tricks by an old dogma: mechanisms of the Organizational/Activational Hypothesis of steroid-mediated sexual differentiation of brain and behavior. Horm Behav 55:655-665. CrossRef Medline

Meda L, Cassatella MA, Szendrei GI, Otvos L Jr, Baron P, Villalba M, Ferrari D, Rossi F (1995) Activation of microglial cells by $\beta$-amyloid protein and interferon- $\gamma$. Nature 374:647-650. CrossRef Medline

Minghetti L, Levi G (1998) Microglia as effector cells in brain damage and repair: focus on prostanoids and nitric oxide. Prog Neurobiol 54:99-125. CrossRef Medline

Minghetti L, Nicolini A, Polazzi E, Créminon C, Maclouf J, Levi G (1997) Prostaglandin $\mathrm{E}_{2}$ downregulates inducible nitric oxide synthase expression in microglia by increasing cAMP levels. Adv Exp Med Biol 433:181184. Medline

Mong JA, McCarthy MM (1999) Steroid-induced developmental plasticity in hypothalamic astrocytes: implications for synaptic patterning. J Neurobiol 40:602-619. CrossRef Medline

Morale MC, Serra PA, L’Episcopo F, Tirolo C, Caniglia S, Testa N, Gennuso F, Giaquinta G, Rocchitta G, Desole MS, Miele E, Marchetti B (2006) Estrogen, neuroinflammation and neuroprotection in Parkinson's disease: glia dictates resistance versus vulnerability to neurodegeneration. Neuroscience 138:869-878. CrossRef Medline 
Mosser DM, Edwards JP (2008) Exploring the full spectrum of macrophage activation. Nat Rev Immunol 8:958-969. CrossRef Medline

Munn NA (2000) Microglia dysfunction in schizophrenia: an integrative theory. Med Hypotheses 54:198-202. CrossRef Medline

Nawa H, Takei N (2006) Recent progress in animal modeling of immune inflammatory processes in schizophrenia: implication of specific cytokines. Neurosci Res 56:2-13. CrossRef Medline

Olesen KM, Auger AP (2005) Sex differences in Fos protein expression in the neonatal rat brain. J Neuroendocrinol 17:255-261. CrossRef Medline

Orikasa C, Kondo Y, Hayashi S, McEwen BS, Sakuma Y (2002) Sexually dimorphic expression of estrogen receptor $\beta$ in the anteroventral periventricular nucleus of the rat preoptic area: implication in luteinizing hormone surge. Proc Natl Acad Sci U S A 99:3306-3311. CrossRef Medline

Park JH, Bonthius PJ, Tsai HW, Bekiranov S, Rissman EF (2010) Amyloid $\beta$ precursor protein regulates male sexual behavior. J Neurosci 30:9967-9972. CrossRef Medline

Polazzi E, Contestabile A (2002) Reciprocal interactions between microglia and neurons: from survival to neuropathology. Rev Neurosci 13:221-242. Medline

Saijo K, Collier JG, Li AC, Katzenellenbogen JA, Glass CK (2011) An ADIOL-ER $\beta$-CtBP transrepression pathway negatively regulates microglia-mediated inflammation. Cell 145:584-595. CrossRef Medline

Schafer DP, Lehrman EK, Kautzman AG, Koyama R, Mardinly AR, Yamasaki R, Ransohoff RM, Greenberg ME, Barres BA, Stevens B (2012) Microglia sculpt postnatal neural circuits in an activity and complementdependent manner. Neuron 74:691-705. CrossRef Medline

Schwarz JM, Sholar PW, Bilbo SD (2012) Sex differences in microglial colonization of the developing rat brain. J Neurochem 120:948-963. CrossRef Medline

Stence N, Waite M, Dailey ME (2001) Dynamics of microglial activation: a confocal time-lapse analysis in hippocampal slices. Glia 33:256-266. CrossRef Medline

Streit WJ, Conde JR, Fendrick SE, Flanary BE, Mariani CL (2005) Role of microglia in the central nervous system's immune response. Neurol Res 27:685-691. CrossRef Medline

Tremblay MÈ, Stevens B, Sierra A, Wake H, Bessis A, Nimmerjahn A (2011) The role of microglia in the healthy brain. J Neurosci 31:16064-16069. CrossRef Medline

Vargas DL, Nascimbene C, Krishnan C, Zimmerman AW, Pardo CA (2005) Neuroglial activation and neuroinflammation in the brain of patients with autism. Ann Neurol 57:67-81. CrossRef Medline

Vegeto E, Bonincontro C, Pollio G, Sala A, Viappiani S, Nardi F, Brusadelli A, Viviani B, Ciana P, Maggi A (2001) Estrogen prevents the lipopolysaccharide-induced inflammatory response in microglia. J Neurosci 21:1809-1818. Medline

World Health Organization (2001) Mental and neurological disorders [fact sheet]. Retrieved from http://www.who.int/whr/2001/media_centre/ en/whr01_fact_sheet1_en.pdf

Wright CL, McCarthy MM (2009) Prostaglandin $E_{2}$-induced masculinization of brain and behavior requires protein kinase $\mathrm{A}, \mathrm{AMPA} / \mathrm{kainate}$, and metabotropic glutamate receptor signaling. J Neurosci 29:13274-13282. CrossRef Medline

Wu CH, Wen CY, Shieh JY, Ling EA (1992) A quantitative and morphometric study of the transformation of amoeboid microglia into ramified microglia in the developing corpus callosum in rats. J Anat 181:423-430. Medline

Yokosuka M, Okamura H, Hayashi S (1997) Postnatal development and sex difference in neurons containing estrogen receptor- $\alpha$ immunoreactivity in the preoptic brain, the diencephalon, and the amygdala in the rat. J Comp Neurol 389:81-93. CrossRef Medline 